\title{
Sulardan Vitamin Arıtımı: Nikotinik Asit Adsorpsiyonu
}

\section{Purification of Vitamins from Waters: Nicotinic Acid Adsorption}

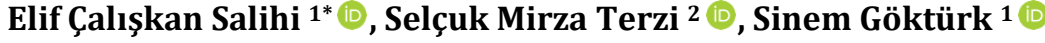 \\ ${ }^{1}$ Marmara Üniversitesi, Eczacılık Fakültesi, Temel Eczacılık Bilimleri Bölümü, İstanbul, TÜRKIYYE \\ ${ }^{2}$ Marmara Üniversitesi, Sağlık Bilimleri Enstitüsü, Eczacılık Temel Bilimleri Anabilim Dalı, İstanbul, TÜRKIYE \\ Sorumlu Yazar / Corresponding Author*: caliskanelif@gmail.com \\ Geliş Tarihi /Received: 24.05 .2020 \\ Araștırma Makalesi/Research Article \\ Kabul Tarihi / Accepted: 30.10.2020 \\ DOI:10.21205/deufmd.2021236811 \\ Atıfssekli/How to cite: SALIHI E.C., TERZI S.M., GÖKTÜRK S. (2021). Sulardan Vitamin Arıtımı: Nikotinik Asit Adsorpsiyonu. DEÜ FMD 23(68), \\ 479-487.
}

$\ddot{0} \mathbf{z}$

Hem farmasötik endüstrisinin atık suları hem de evsel kullanım sonucu doğadaki su ortamlarına karışan biyomoleküllerden biri olan nikotinik asitin sulardan arıtılması insan ve çevre sağlığı üzerindeki olumsuz etkilerinden dolayı önem tașımaktadır. Bu sebeple bu çalıșmada nikotinik asitin sulardan arıtılması maliyet ve kullanım açısından pek çok avantaj taşıyan adsorpsiyon yöntemi kullanılarak incelenmiştir. Adsorban olarak seçilen granüler ticari aktif karbonun nikotinik asiti sulu ortamdan uzaklaştırma etkinliği ve sıcaklık, pH gibi faktörlerin adsorpsiyon sürecine olan etkisi araştırılmıştır. Farklı başlangıç derişimlerindeki nikotinik asit çözeltileri kullanılarak çalkalama süresinin adsorpsiyon miktarı üzerindeki etkisi takip edilerek öncelikle adsorpsiyonun dengeye gelme süresi belirlenmiștir. Elde edilen kinetik veriler Lagergren 1. derece ve Yalancı 2. derece eşitlikleri ile modellenmiştir ve verilerin Lagergren 1. derece eşitliğine daha iyi uyduğu görülmüştür. Adsorpsiyon mekanizmasında tanecik içi difüzyonunun rol oynadığı ortaya koyulmuş ve hızı kontrol eden tek adımın tanecik içi difüzyon olmadığı anlaşılmıştır. Denge süresi boyunca yürütülen çalıșmalardan elde edilen denge verileri ise Langmuir ve Freundlich izoterm eșitlikleri kullanılarak modellenmiș ve izoterm sabitleri hesaplanmıștır. Giles sınıflandırmasına göre L tipine uyduğu gözlemlenen nikotinik asit adsorpsiyonunun Langmuir denklemine daha iyi uyduğu tespit edilmiş ve adsorpsiyon kapasitesinin sıcaklığın düșmesi ile arttı̆̆ı, ortamın pH değerinin değişmesinden ise önemli ölçüde etkilendiği tespit edilmiştir.

Anahtar Kelimeler: Nikotinik asit, Aktif karbon, Adsorpsiyon, Vitamin, Biyomolekül

\section{Abstract}

Purification of nicotinic acid, one of the biomolecules contaminates natural waters as a result of both waste waters of pharmaceutical industry and household usage, is important due to negative effects on human and environmental health. Therefore, the removal of nicotinic acid from waters using adsorption method which has many advantages related to cost and utilization. Nicotinic acid removal performance of commercial activated carbon selected as adsorbent, and the effect of factors such as temperature, $\mathrm{pH}$ on the adsorption process was investigated. Time to reach equilibrium was determined initially by following up the effect of shaking time on adsorption quantity using nicotinic acid solutions having different initial concentrations. Kinetic data obtained was modeled by using Lagergren 1st order and Pseudo 2nd order equations and it was seen that experimental data better 
fit the Lagergren 1st order equation. It was introduced that intraparticle diffusion plays a role in the adsorption mechanism and it is understood that intraparticle diffusion is not the only step controlling the adsorption rate. Equilibrium data were modeled by using Langmuir and Freundlich equations and isotherm constants were calculated. It was determined that nicotinic acid adsorption which is L-type according to Giles classification, fits better to the Langmuir equation and the adsorption capacity increases with a decrease in the temperature while any change in the $\mathrm{pH}$ of the medium effects it considerably.

Keywords: Nicotinic acid, Activated carbon, Adsorption, Vitamin, Biomolecule

\section{Giris}

Biyomoleküllerin adsorpsiyonu ilaç taşınımı, biyosensör ve tıbbi cihaz kaplamaları gibi alanlardaki potansiyel uygulamalarından dolayı büyük bir önem taşır. Ayrıca biyomoleküllerin geri kazanımı ve sulardan arıtılması açısından da önemlidir [1-3]. Benzoik asit ve türevleri gıda, farmasötik, tekstil ve kozmetik sektörlerinde bir çok amaçla kullanıldıklarından, evsel ve endüstriyel atık sularda çoğunlukla bulunurlar. Çevrede yaratacakları zararlı etkiler sebebiyle, aromatik asitleri içeren atık suların doğadaki su ortamlarına karışmadan önce arıtılmaları gerekir [4]. Adsorpsiyon yöntemi organik kirleticilerin sulardan uzaklaştırılması konusunda bir çok avantaj taşıması ve maliyetinin düșük olması sebebiyle öne çıkmaktadır. Aktif karbon, organik moleküllerin adsorpsiyonu için toz ya da granüler halde kullanılan en eski ve kullanımı yaygın olan adsorban maddelerden biridir. Literatürdeki çalıșmalar aktif karbonun organik maddelerin adsorpsiyonu için etkili olarak kullanıldığını göstermektedir [5-13].

Biyouyumluluğu iyi bilinen karbon, vitaminler ve proteinler gibi biyomoleküllerin adsorpsiyonu için iyi bir alternatiftir. Biyomolekül adsorpsiyonunun hem ilaç endüstrisi hem de çevre uygulamaları açısından uygunluk taşır [1]. Bhatia ve diğ., izo-nikotinik asidin modifiye edilmiș karbon nanotüpler ve aktif karbon esasl kompozitler üzerindeki adsorpsiyonunu incelemişlerdir $[14,15]$. Nikotinik asitin adsorpsiyonu konusunda literatürde çok sınırlı sayıda çalıșma bulunmaktadır. Datta ve diğ., nikotinik asit adsorpsiyonunu manyetik aktif karbon kullanarak incelemişlerdir [16]. Dancu ve diğ., nano boyuttaki hidroksiapatit ve modifiye edilmiș hidroksiapatit kullarak nikotinik asit adsorpsiyonunu çalıșmıșlardır [17]. Hui-Wen ve diğ. ise nikotinik asitin demir yüzeyi üzerindeki adsorpsiyonunu incelemiș ve adsorpsiyon mekanizmasını ortaya koymuşlardır [18].

Vitaminler, insanların sağlıklı gelişimi için gerekli olan bileşiklerdir ve suda çözünen ya da yağda çözünen vitaminler olarak sinıflandırılırlar [19]. Niasin ya da B3 vitamini olarak da bilinen nikotinik asit, suda çözünen ve diyetin gerekli bir parçası olan bir mikrobesindir. Bununla birlikte kimya, biyokimya ve terapötik alanda geniș bir uygulaması bulunmaktadır. Gıda katkılarında, hayvan yemlerinde, kozmetikte ve bilim teknolojinin diğer bir çok alanında genișleyen uygulama alanları vardır [16]. Ayrıca dislipidemi tedavisinde yaygın olarak kullanılmakta ve yüksek kolestrol seviyelerini düşürmek ve kontrol etmeye yardımcl olacak çok önemli bir hipolipidemik ilaç olduğu düşünülmektedir [17].

Üretimi yapan farmasötik endüstrisi, kimyasal sentez prosesisin atık sularını kısmen arıtılmış ya da arıtılmamış olarak doğaya salmaktadır. Bu atık sular çözücüler, katkı maddeleri, reaktanlar, ara ürünler ve farmasötik ürünler içerirler. Farmasötiklerin doğadaki su ortamlarına karışmasının bir diğer yolu ise, insanların tüketimi sonucu kısmen ya da tamamen metabolize olmuş halde vücuttan atılmasıdır [20,21]. Nikotinik asit gibi biyolojik olarak aktif moleküller içeren bu atık sular doğadaki su ortamlarına karışarak çevre ve canlı sağlığı üzerinde bir çok zararlı etkiye yol açabilir. İnsanlar tarafından nikotinik asitin yüksek dozlarının alınması kan damarlarının genişleyerek tansiyonun düşmesi, ciltte kızarma ve kaşınma, kuru cilt, deri döküntüsü, egzema, doğum kusuru, hiperürisemi, kan şekeri yükselmesi, makülopati gibi sağlık sorunlarına yol açabilir. Ayrıca hayvan sağlığını da benzer şekilde tehdit eder $[17,22]$.

Nikotinik asitin dünya çapında yıllık üretiminin yaklașık 35000-40000 ton arasında olduğu düşünüldüğünde [23] ve çevre ile sağlık 
üzerindeki bütün bu olumsuz etkilerinden dolayı, nikotinik asit içeren suların arıtılması büyük bir önem taşımaktadır. Bununla birlikte, vitaminler gibi biyobileşiklerin kimyasal yolla üretiminin maliyeti çok yüksektir ve bu yüzden genellikle bitki ya da hayvansal ekstrelerden üretilirler. Dolayısıyla bu üretimde etkili bir ayırma ve saflaştırma yöntemi de önem taşımaktadır. Arıtma ve saflaştırma için uygun bir yöntemin geliştirilmesi gerekmektedir [19, 24].

Literatürde nikotinik asidin adsorpsiyonu için ticari aktif karbonun kullanıldığı bir çalıșmaya rastlanmamıștır. Bu bağlamda, bu çalıșmanın amacı nikotinik asidin ticari granüler aktif karbon üzerindeki adsorpsiyonunun incelenmesidir. $\mathrm{Bu}$ çalışma kapsamında, nikotinik asidin granüler aktif karbon üzerindeki adsorpsiyonu farklı çalıșma koșulları için incelenmiş [25], adsorpsiyon kapasitesi ortaya konmuș ve nikotinik asit ile aktif karbon arasındaki etkileşimler açıklanmıştır. Nikotinik asit adsorpsiyonu aynı koşullarda farklı adsorbanlar ile de yürütülerek aktif karbonun kapasitesi diğer adsorbanlar ile karşılaştırılmıştır.

\section{Materyal ve Metot}

\subsection{Kullanılan malzemeler}

Granüler aktif karbon Merck firmasından alınmıștır ve kullanılmadan önce $100^{\circ} \mathrm{C}$ sıcaklıkta 24 saat boyunca kurutulmuștur. Kullanılan aktif karbonun gaz adsorpsiyonu yöntemi ile yüzey alanı ve gözenekliliği ölçülmüş ve BET yüzey alanı $792 \mathrm{~m}^{2} / \mathrm{g}$, mikrogözenek alanı $473 \mathrm{~m}^{2} / \mathrm{g}$, mikrogözenek hacmi 0,193 $\mathrm{m}^{3} / \mathrm{g}$ olarak bulunmuştur. Sifır yük noktası (pHPZc) değeri kütle titrasyonu yöntemi kullanılarak 9,59 olarak bulunmuştur [26]. Nikotinik asit (B3 vitamini) Sigma-Aldrich firmasından alınmıștır. Nikotinik asitin özellikleri Tablo 1'de verilmiştir.

Tablo 1. Nikotinik asidin fiziksel ve kimyasal özellikleri.

\begin{tabular}{|c|c|c|c|c|}
\hline $\begin{array}{c}\text { Molekül } \\
\text { formülü }\end{array}$ & $\begin{array}{c}\text { Mol } \\
\text { ağırlığı }\end{array}$ & Çözünürlüğü & $\begin{array}{c}\text { pKa } \\
{[27]}\end{array}$ & $\lambda_{\text {maks }}$ \\
\hline $\begin{array}{c}123,11 \\
\mathrm{O} / \mathrm{mol}\end{array}$ & $\begin{array}{c}\text { Suda iyi } \\
\text { çözünmektedir. }\end{array}$ & $\begin{array}{c}2,14 \\
4,82\end{array}$ & $\begin{array}{c}263 \\
\mathrm{~nm}\end{array}$ \\
\hline
\end{tabular}

Nikotinik asit adsorpsiyonu için kapasitesi test edilen diğer adsorbanlar (bentonit, talk, Fuller's earth), Sigma-Aldrich firmasından temin edilmiștir. Adsorbanlar yıkama ve kurutma dışında herhangi bir ön işlem yapılmadan kullanılmıştır.

\subsection{Adsorpsiyon deneyleri}

Adsorpsiyon deneylerinden önce farklı miktarlarda adsorban ve adsorbat kullanılarak ön denemeler yapılmış ve en uygun adsorban/adsorbat oranı belirlenmiştir. Adsorpsiyon deneyleri $50 \mathrm{mg}$ adsorban ve 100 mL nikotinik asit çözeltileri kullanılarak 250 mL'lik erlenlerde yürütülmüştür. Adsorpsiyon sirasında ve sonrasinda alınan numunelerden granüler aktif karbon santrifüj kullanılarak ayrılmıştur ve absorbansları Shimadzu (UV1700) marka UV-görünür bölge spektrofotometresi kullanılarak 263 nm'de ölçülmüştür. Önceden hazırlanmış kalibrasyon eğrileri yardımıyla numunelerin derișimleri hesaplanmıștır. Yapılan her deney $3 \mathrm{kez}$ tekrarlanmıştır.

Nikotinik asit adsorpsiyonunun denge süresini belirlemek için 25 ve $50 \mathrm{mg} / \mathrm{L}$ başlangıç derişimlerindeki adsorbat çözeltileri kullanılmıștır. Belirli zaman aralıklarında alınan numunelerin absorbansları ölçülmüş ve adsorbat derişiminin zamana göre değişimi takip edilerek denge süresi belirlenmiştir. Ölçülen absorbans değerleri ve kalibrasyon eğrileri aracılığıyla herhangi bir $\mathrm{t}$ anındaki adsorplanan madde miktarı (q; $\mathrm{mg} / \mathrm{g}$ ) hesaplanmıștır (1). $\mathrm{C}_{0}$; bașlangıç derişimini (mg/L), C; herhangi bir $\mathrm{t}$ (saat) anındaki derişimi (mg/L), V; çözelti hacmini (L), $m$ ise adsorban miktarını $(\mathrm{g})$ ifade etmektedir.

$$
q=\frac{\left(C_{0}-C\right) V}{m}
$$

Lagergren hız denklemi kullanılarak zaman $(\mathrm{t})$ ve In $\left(\mathrm{q}_{\mathrm{e}} \mathrm{q}\right)$ değerleri arasında çizilen grafiklerin eğim ve kesme değerlerinden Lagergren modeli için kinetik parametreler hesaplanmıștır. qe; denge anındaki q değerini ifade etmektedir. Yalancı ikinci derece hız denklemi kullanılarak ise $t$ ve $t / q$ değerleri arasında çizilen grafiklerin eğim ve kesme değerlerinden ise Yalancı ikinci derece modelinin kinetik parametreleri hesaplanmıştır.

Aktif karbonun nikotinik asit için adsorpsiyon kapasitesinin belirlenmesi için Langmuir ve Freundlich izotermleri çizilmiștir. Farklı başlangıç derişimleri kullanılarak sabit sıcaklıklarda adsorpsiyon deneyleri yapılmıștır. $\mathrm{Bu}$ deneylerde çalkalama süresi olarak daha 
önce belirlenen denge süresi kullanılmıștır. Çizilen izotermlerden ilgili izoterm sabitleri hesaplanmıştır. Giles izotermi de çizilerek adsorpsiyonun tipi tespit edilmiştir. Nikotinik asit adsorpsiyonuna sıcaklığın etkisini incelemek amacıyla denge deneyleri farklı sıcaklıklarda yürütülmüştür. Adsorpsiyon sürecine ortam $\mathrm{pH}^{\prime} ı$ nın etkisinin belirlenmesi amacıyla ise, farklı pH değerlerinde hazırlanan çözeltiler kullanılarak adsorpsiyon deneyleri aynı düzende tekrar edilmiştir.

Aktif karbonun kapasitesinin karşılaştırılması amacıyla nikotinik asit adsorpsiyonu aynı adsorban/adsorbat oranı ve derișim aralığ kullanılarak farklı adsorbanlar ile de yürütülmüştür.

\section{Bulgular}

Nikotinik asitin granüler aktif karbon üzerindeki adsorpsiyonuna çalkalama süresinin etkisi $25 \mathrm{mg} / \mathrm{L}$ ve $50 \mathrm{mg} / \mathrm{L}$ başlangıç derişimleri kullanılarak $25^{\circ} \mathrm{C}$ 'da çalıșıldı ve belli aralıklarla ölçülen derişim değerleri ile derişimin zamanla değişimi grafiği çizildi (Şekil 1). Şekilden de görüldüğü gibi bu adsorpsiyonun dengeye gelme süresi 5,5 saattir.

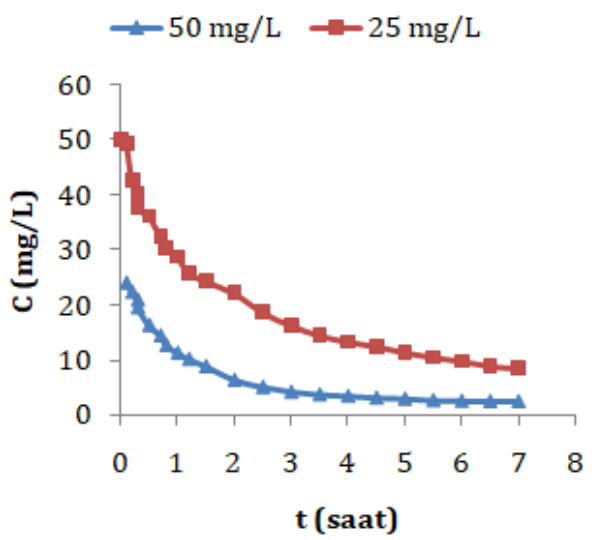

Şekil 1. Nikotinik asitin aktif karbon üzerindeki adsorpsiyonunda derişimin zamanda değișimi.

Derișimin zamanla değişimine ait veriler Lagergren 1. derece ve Yalancı 2. Derece hiz eşitlikleri kullanılarak modellendi ve kinetik parametreler hesaplandı (Tablo 2, grafikler gösterilmemiștir). Tablodan da görüldüğü gibi, nikotinik asit adsorpsiyonu Lagergren birinci derece eșitliğine daha iyi uymuștur. Ayrıca tanecik içi difüzyon grafikleri çizildi (Şekil 2.a ve b). Tanecik içi difüzyon grafiklerinde farklı tipte değișimlerin olduğu üç farklı bölge görülmektedir. Birinci kısımda görülen eğrisel değişim sınır tabaka etkisini göstermektedir. İkinci kısımda değișim doğrusal olarak devam etmektedir ve bu doğrusal kısım tanecik içi difüzyonun varlığını gösterir. Nikotinik asit adsorpsiyonunda tanecik içi difüzyon rol oynamaktadır. Üçüncü kısımda görülen plato ise denge bölgesini gösterir. İkinci kısımda görülen doğrunun orijinden geçmiyor oluşu bu adsorpsiyonda hızı kontrol eden tek adımın tanecik içi difüzyon olmadığının göstergesidir [10].

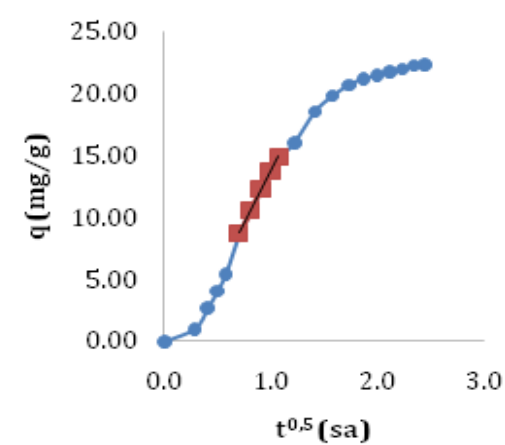

(a)

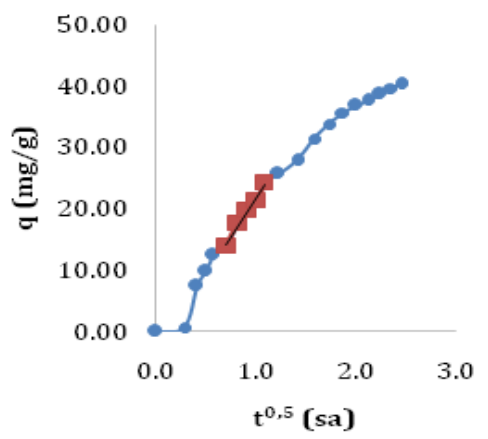

(b)

Şekil 2. Nikotinik asitin aktif karbon üzerindeki adsorpsiyonuna ait $25 \mathrm{mg} / \mathrm{L}\left(\mathrm{a}, \mathrm{R}^{2}=0,998\right)$ ve 50 $\mathrm{mg} / \mathrm{L}\left(\mathrm{b}, \mathrm{R}^{2}=0,987\right)$ başlangıç derişimleri için tanecik içi difüzyon grafikleri. 
Tablo 2. Nikotinik asidin aktif karbon üzerindeki adsorpsiyonuna ait kinetik veriler.

\begin{tabular}{ccccccc}
$\begin{array}{c}\mathrm{C}_{0} \\
(\mathrm{mg} / \mathrm{L})\end{array}$ & \multicolumn{2}{c}{ Lagergren modeli } & \multicolumn{3}{c}{ Yalancı ikinci derece modeli } \\
\hline & $\mathrm{k}_{1}(1 / \mathrm{sa})$ & $\mathrm{q}_{1}(\mathrm{mg} / \mathrm{g})$ & $\mathrm{R}^{2}$ & $\mathrm{k}_{2}(\mathrm{~g} / \mathrm{mg} \mathrm{sa})$ & $\mathrm{q}_{2}(\mathrm{mg} / \mathrm{g})$ & $\mathrm{R}^{2}$ \\
\hline $25 \mathrm{mg} / \mathrm{L}$ & 0,849 & 21,31 & 0,998 & 0,027 & 28,16 & 0,980 \\
\hline $50 \mathrm{mg} / \mathrm{L}$ & 0,648 & 36,21 & 0,992 & 0,015 & 49,26 & 0,982 \\
\hline
\end{tabular}

Tanecik içi difüzyon grafiklerinin doğrusal başlangıç derişimleri için sırasıyla kısmının eğiminden tanecik içi difüzyon $16,63 \mathrm{mg} / \mathrm{g} \mathrm{sa}{ }^{1 / 2}$ ve $26,16 \mathrm{mg} / \mathrm{g} \mathrm{sa}^{1 / 2}$ olarak katsayısı $\left(\mathrm{k}_{\mathrm{d}}\right)$ nikotinik asitin 25 ve $50 \mathrm{mg} / \mathrm{L}$ hesaplanmıştır.

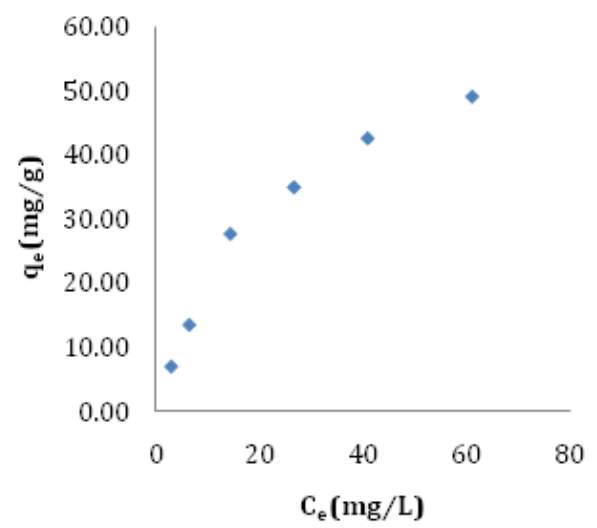

(a)

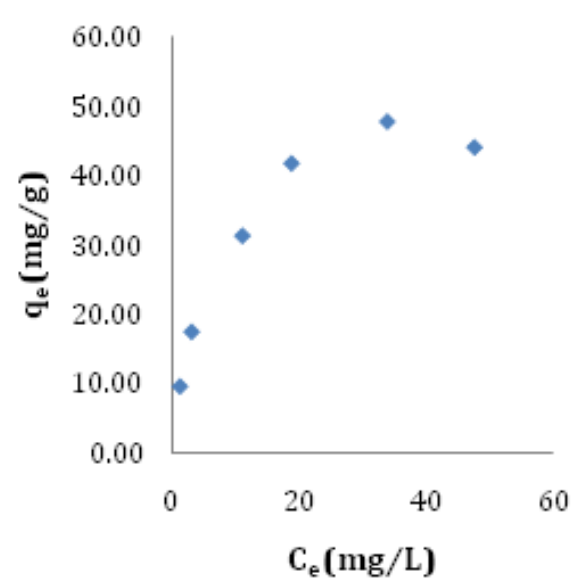

(c)

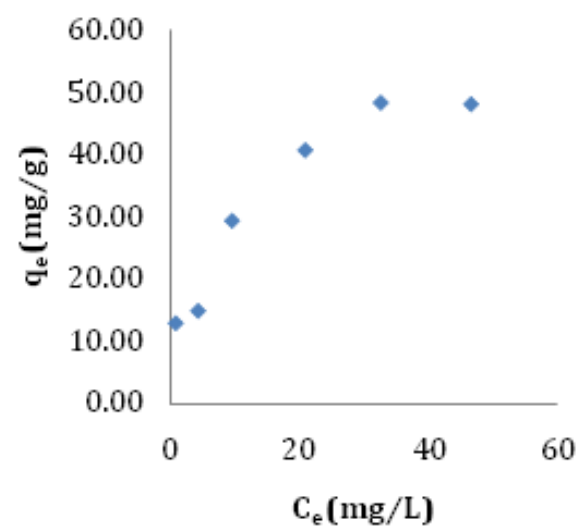

(b)

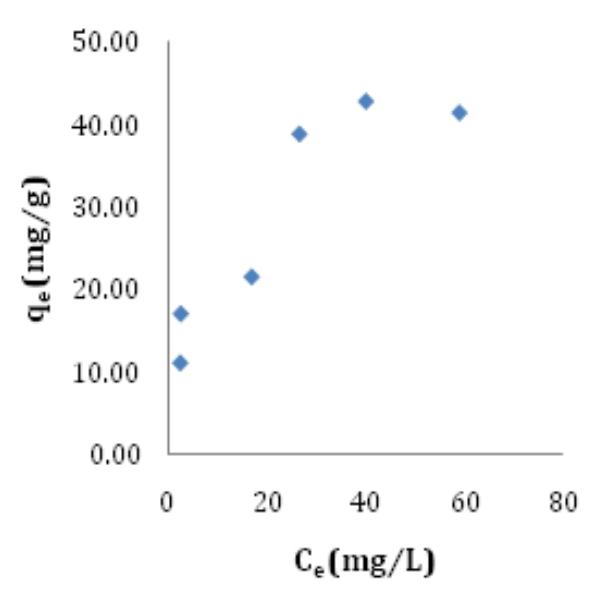

(d)

Şekil 3. Nikotinik asidin aktif karbon üzerinde çeşitli sıcaklıklarda (a: $15^{\circ} \mathrm{C}, \mathrm{b}: 25^{\circ} \mathrm{C}, \mathrm{c:} 37^{\circ} \mathrm{C}$ ve $\mathrm{d}: 47^{\circ} \mathrm{C}$ ) yürütülen adsorpsiyonlarına ait Giles izotermleri. 
DEÜ FMD 23(68), 479-487, 2021

Tablo 3. Nikotinik asidin aktif karbon üzerindeki adsorpsiyonuna ait izoterm parametreleri

\begin{tabular}{|c|c|c|c|c|c|c|}
\hline & \multicolumn{3}{|c|}{ Langmuir izotermi } & \multicolumn{3}{c|}{ Freundlich izotermi } \\
\hline $\mathrm{T}\left({ }^{\circ} \mathrm{C}\right)$ & $\mathrm{Q}(\mathrm{mg} / \mathrm{g})$ & $\mathrm{b}(\mathrm{L} / \mathrm{g})$ & $\mathrm{R}^{2}$ & $\mathrm{~N}$ & $\mathrm{~K}$ & $\mathrm{R}^{2}$ \\
\hline 15 & 70,92 & 0,04 & 0,991 & 0,65 & 3,84 & 0,966 \\
\hline 25 & 56,18 & 0,14 & 0,969 & 0,36 & 12,52 & 0,905 \\
\hline 37 & 50,51 & 0,20 & 0,989 & 0,42 & 10,30 & 0,956 \\
\hline 47 & 48,54 & 0,10 & 0,929 & 0,88 & 9,38 & 0,876 \\
\hline
\end{tabular}

Granüler aktif karbon üzerindeki nikotinik asit adsorpsiyonu 10-100 $\mathrm{mg} / \mathrm{L}$ derişim aralığında $15^{\circ} \mathrm{C}, 25^{\circ} \mathrm{C}, 37^{\circ} \mathrm{C}$ ve $47^{\circ} \mathrm{C}$ sıcaklıklarda çalışıldı. Nikotinik asitin granüler aktif karbona olan ilgisinin belirlenmesi amaciyla Giles izotermleri çizildi (Şekil 3). qe ile Ce arasında çizilen grafikler Giles sınıflandırmasına göre L tipine uymaktadır. L tipi izotermin başlangıç eğiminin değişimi, adsorbandaki aktif bölgelerin dolması sonucu adsorbat moleküllerinin boș adsorpsiyon bölgeleri bulmalarının zorlaştığını, moleküllerin dikey olarak yerleşmediğini ve çözücü ile kuvvetli bir yarışmanın olmadığını gösterir [28].

Elde edilen denge verileri Langmuir ve Freundlich izotermleri ile modellendi. Adsorpsiyon kapasitesinin belirlenmesi amacıyla Ce/qe ve Ce arasında çizilen Langmuir izotermlerinin (Grafikler gösterilmemiștir.) eğim ve kesmelerinden Langmuir sabitleri $Q$ ve b hesaplandı. In qe ile In Ce arasında çizilen Freundlich izoterminin (Grafikler gösterilmemiştir.) eğim ve kesmelerinden Freundlich sabitleri $\mathrm{n}$ ve $\mathrm{k}$ hesaplandı. Bulunan izoterm parametreleri Tablo 3'te verildi. Nikotinik asit adsorpsiyonunun Langmuir modeline Freundlich modelinden daha iyi uyduğu tablodan görülmektedir.

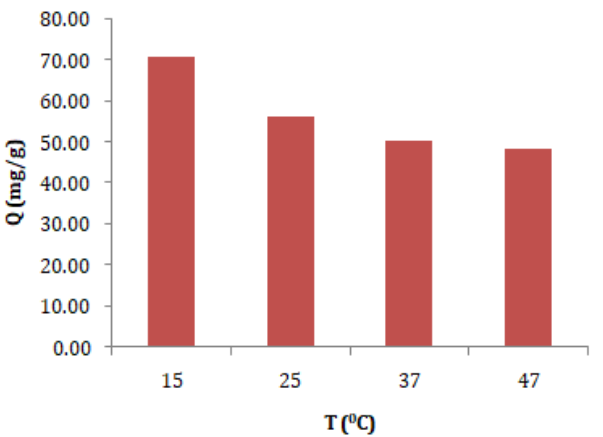

Şekil 4. Nikotinik asitin aktif karbon üzerindeki adsorpsiyonuna sıcaklık etkisi

Ayrıca Langmuir denklemi kullanılarak çalıșılan her sicaklık için hesaplanan adsorpsiyon kapasitesi değerleri karşılaștırıldı ve nikotinik asidin aktif karbon üzerindeki adsorpsiyonunda sıcaklığın düşmesinin adsorpsiyon kapasitesini arttırdığı görüldü (Şekil 4). Sıcaklığın etkisiyle gerçekleşen adsorpsiyon kapasitesindeki bu değișim ekzotermik ve fiziksel bir adsorpsiyon sürecine işaret etmektedir. Sıcaklık azaldıkça nikotinik asit molekülleri ile aktif karbon yüzeyi arasındaki çekim kuvvetleri güçlenmiştir [29].

Adsorpsiyona ortam pH'ının etkisi 1,2-11 pH değerleri aralığında incelendi ve ortam pH'ının nikotinik asitin aktif karbon üzerindeki adsorpsiyonuna önemli ölçüde etki ettiği görüldü (Şekil 5). 
DEÜ FMD 23(68), 479-487, 2021

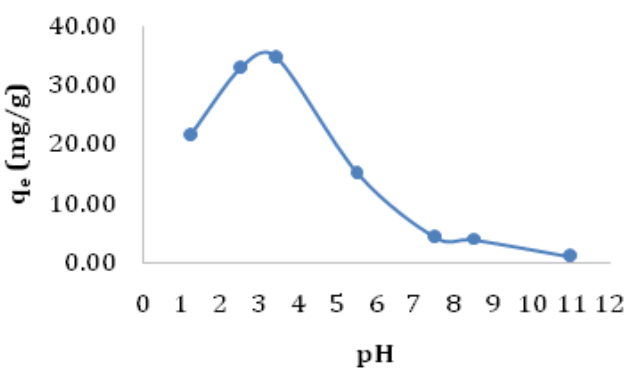

Şekil 5. Nikotinik asitin aktif karbon üzerindeki adsorpsiyonuna $\mathrm{pH}$ etkisi

Ortam pH'ının artması yaklaşık pH 3 değerine kadar adsorpsiyonda artış sağlamış ancak bu değerden sonra önemli ölçüde bir azalma gözlenmiştir. Nikotinik asit adsorpsiyonu için en yüksek kapasite değeri yaklaşık pH 3 değerinde gözlenmiştir. Ortam pH'ının adsorpsiyon üzerindeki etkisi hem nikotinik asitin sulu ortamdaki türlenmesi (pKa değerleri= 2,14; 4,82 [27]) hem de aktif karbonun pHpzc değeri $(9,59)$ dikkate alınarak değerlendirildi. $\mathrm{pH} \quad 2,14$ değerinden sonra adsorpsiyonda gözlenen artış pozitif yüklü aktif karbon yüzeyi ile artık negatif yük de taşıyan nikotinik asit arasında elektrostatik çekimin devreye girmesi sonucu olmuştur. Çünkü bu bölgede nikotinik asit molekülü karboksil grubundaki hidrojeni ortama vererek negatif yük de kazanmıștır. Nikotinik asit ayrıca piridin halkasındaki azotun tașıdığı pozitif yük sayesinde aktif karbon yüzeyinde katyon değişimi yoluyla da adsorplanabilmektedir. Fakat 4,82'den daha yüksek $\mathrm{pH}$ değerlerinde nikotinik asidin ortamdaki baskın türü anyoniktir. Nikotinik asit aktif karbon yüzeyine sadece zayıf fiziksel adsorpsiyon yoluyla adsorbe olabilmektedir. Ortam pH's, aktif karbonun pHpzc değerine yaklaştıkça yüzeyindeki pozitif yükler azalır ve bunun sonucu olarak adsorpsiyon kapasitesi de önemli ölçüde düşer. pH 11 değerinde ise aktif karbon yüzeyi artık negatif yük taşımaktadır ve anyonik nikotinik asit molekülü ile arasındaki elektrostatik itme moleküllerin adsorbe olmasına engel olur. Ortam pH'ının nikotinik asit adsorpsiyonuna olan etkisi, bu adsorpsiyona sicaklık etkisinin tespit edildiği deney sonuçları ile uyum göstermiştir.

Kullanılan ticari aktif karbonun nikotinik asidi uzaklaştırma kapasitesi diğer potansiyel adsorbanlar ile karşılaștırılmıştır (Şekil 6). Bulunan sonuçlar Şekil 6'da özetlenmiştir.
Karşılaștırılan kapasite (Q) değerleri Langmuir modeli kullanılarak bulunmuștur. Aktif karbonun adsorpsiyon kapasitesi diğer adsorbanlara göre önemli bir üstünlük göstermiştir.

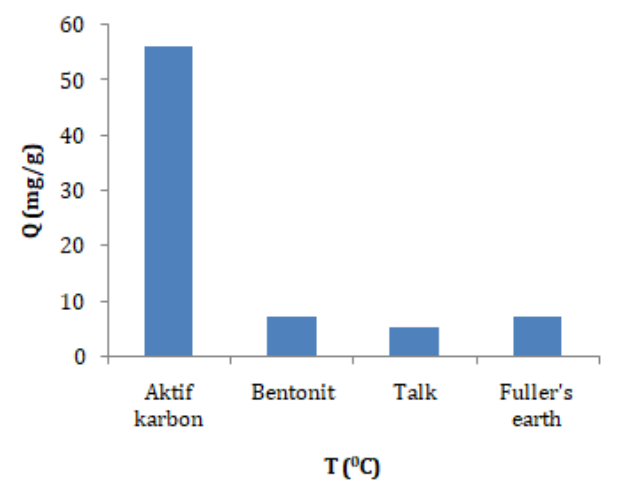

Şekil 6. Nikotinik asit adsorpsiyonu için aktif karbon ve diğer adsorbanların karşılaştırılması (Bentonit, Talk ve Fuller's earth için $\mathrm{R}^{2}$ değerleri sirasılya: 0,$989 ; 0,977 ; 0,988)$.

\section{Tartışma ve Sonuç}

Vitaminler gibi biyomoleküllerin doğadaki su ortamlarına karıșmasının önlenmesi için, atık sulardan arıtılmaları gerekmektedir. $\mathrm{Bu}$ çalışmada, atık suların arıtılmasında maliyet ve işletim avantajları sağlayan adsorpsiyon yöntemi [30] ve ticari granüler aktif karbon kullanılarak sulardan nikotinik asit (B3 vitamini) giderimi incelenmiştir. Nikotinik asitin aktif karbon üzerindeki adsorpsiyonunun 5,5 saatte dengeye geldiği görülmüștür. Kinetik veriler Lagergren birinci derece ve Yalancl ikinci derece denklemleri kullanılarak modellenmiş ve bu adsorpsiyonun Lagergren birinci derece modeline daha iyi uyduğu görülmüștür. Adsorpsiyon mekanizmasında tanecik içi difüzyonun rol oynadığı ve film difüzyonu ile birlikte hızı kontrol eden adımlar oldukları tespit edilmiştir.

Nikotinik asit adsorpsiyonu Giles sınıflandırmasına göre L tipine uymuştur. $15^{\circ} \mathrm{C}$, $25^{\circ} \mathrm{C}, 37^{\circ} \mathrm{C}$ ve $47^{\circ} \mathrm{C}$ 'da elde edilen denge verileri Langmuir ve Freundlich izotermleri kullanılarak modellenmiştir. Adsorpsiyon süreci Langmuir denklemine Freundlich denkleminden daha iyi uymuştur ve sıcaklıktaki azalma ekzotermik ve fiziksel bir adsorpsiyonun göstergesi olarak adsorpsiyon kapasitesini arttırmıștır. En yüksek 
kapasite değeri 70,92 $\mathrm{mg} / \mathrm{g}$ olarak bulunmuștur. Vücut sıcaklığı olan $37^{\circ} \mathrm{C}$ 'da ise kapasite değeri 50,51 $\mathrm{mg} / \mathrm{g}$ olarak bulunmuştur. $\mathrm{Bu}$ durum aktif karbonun nikotinik asitin sulardan gideriminde kullanılabileceği kadar aynı zamanda aşırı doz alımlarında bu maddenin toksik etkilerinin vücuttan uzaklaştırılması için mideden ve bağırsaktan adsorpsiyon amaciyla gastrointestinal adsorban olarak da kullanılabileceği ve adsorpsiyon kapasitesi konusunda fikir vermiștir. Asidik ortamda adsorpsiyonun yüksek olması, bu avantajı kuvvetlendirmektedir.

Nikotinik asidin adsorpsiyonu konusunda literatürde çok sınırlı sayıda çalışma bulunmaktadır. Ancak, bulduğumuz kapasite değerlerini nikotinik aside yapı olarak benzerlik gösteren izoniyazid'in aktif karbon üzerindeki adsorpsiyonunun [31] kapasite değerleri ile karşılaștıracak olursak, kapasite değeri moleküllerin taşıdığı kısmi yüklerin adsorpsiyondaki önemli etkisini gösterir şekilde izoniyazid adsorpsiyonu için daha yüksek bulunmuştur. $\mathrm{Bu}$ benzer iki molekülün adsorpsiyonuna ortam pH'ının etkisi ise benzer eğilimi göstermektedir.

Ortam pH'ı nikotinik asit adsorpsiyonuna önemli ölçüde etki etmiştir ve en yüksek kapasite değeri yaklaşık pH 3'te bulunmuştur. Fiziksel adsorpsiyonla atık giderimi aktif karbonun kullanım sonrası rejenerasyonu açısından avantaj tașımaktadır. Adsorpsiyonun ortam pH'ından önemli ölçüde etkileniyor olmasından dolayı, ilerideki çalıșmalar için nikotinik asit gideriminde kullanılmıs olan aktif karbonun bazik ortamda rejenerasyonu planlanmaktadır.

$\mathrm{Bu}$ çalışmada kullanılan ticari granüler aktif karbonun sulardan biyomolekülleri uzaklaştırmak için etkili olduğu model vitamin olarak seçilen nikotinik asit üzerinde gösterilmiștir. Mevsimsel sicaklık değişimlerinin adsorpsiyon üzerindeki etkisi ortaya konmuştur. Elde edilen bilgilerin, geleneksel atık su arıtma tesislerine verilmeden önce ön bir işlemden geçirilmesi gereken özellikle farmasötik endüstrisi atık sularının ve evsel atık suların arıtımında faydalı olacağı düşünülmektedir.

\section{Kaynakça}

[1] The Carbon Society of Japan. 1996. Introduction of New Carbon Materials. Realize Inc. Press.

[2] Shen, W., Wang, H., Guan, R., Li, Z. 2008. Surface modification of activated carbon fiber and its adsorption for vitamin B1 and folic acid, Colloids and Surfaces A: Physicochemical and Engineering Aspects, Cilt 331(3), s. 263-267.

[3] Ana María, R., Otero, M., Rodrigues, A.E. 2004 Recovery of Vitamin B12 and cephalosporin-C from aqueous solutions by adsorption on non-ionic polymeric adsorbents, Separation and Purification Technology, Cilt 38(1), s. 85-98.

[4] Howe-Grant, M. 1992. Kirk-Othmer Encyclopedia of Chemical Technology (vol. 4). John Wiley \& Sons, New York.

[5] Ayrancl, E., Duman, O. 2006. Adsorption of aromatic organic acids onto high area activated carbon cloth in relation to wastewater purification, Journal of Hazardous Materials, Cilt 136(3), s. 542-552.

[6] Ania, C.O., Parra, J.B., Pis, J.J. 2002. Influence of oxygen-containing functional groups on activated carbon adsorption of selected organic compounds, Fuel Process. Technol. Cilt 79, s. 265-271.

[7] Abe, M., Kawashima, K., Kozawa, K., Sakai, H., Kaneko, K. 2000. Amination of activated carbon and adsorption characteristics of its aminated surface, Langmuir. Cilt 16, s. 5059-5063.

[8] Mahramanlioglu, M., Bicer, I., Misirli, T., Caliskan, E., Guel, S., Misirli, C. 2006. The removal of anionic naphthalene derivatives by the adsorbents produced from used tires. Fresenius Environmental Bulletin. Cilt 15, s. 1150-1155.

[9] Haghseresht, F., Nouri, S., Lu, G.Q. 2002. Effects of the solute ionization on the adsorption of aromatic compounds from dilute aqueous solutions by activated carbon. Langmuir. Cilt 18, s. 1574-1579.

[10] Çalışkan, E., Göktürk, S. 2010. Adsorption characteristics of sulfamethoxazole and metronidazole on activated carbon. Separation Science and Technology, Cilt 45(2), s. 244-255.

[11] Cantürk Talman, R.Y., Çalışkan Salihi, E., Göktürk, S., Baștuğ, A.S. 2015. Removal of ethacridine lactate from aqueous solutions onto bentonite and activated carbon. Fresenius Environmental Bulletin, Cilt 24(11), s. 3603-3608.

[12] Caliskan Salihi, E. 2017 Adsorption of Metamizole sodium by activated carbon in simulated gastric and intestinal fluids. Journal of the Turkish Chemical Society, Section A: Chemistry, Cilt 5(1), s. 237-246.

[13] Otero, M., Grande, C.A., Rodrigues, A.E. 2004. Adsorption of salicylic acid onto polymeric adsorbents and activated charcoal. Reactive \& Functional Polymers, Cilt 60, s. 203-213.

[14] Bhatia, D., Datta, D., Joshi, A., Gupta, S., Gote, Y. 2019. Adsorption of isonicotinic acid from aqueous solution using multi-walled carbon nanotubes/Fe304. Journal of Molecular Liquids, Cilt 276, s. 163-169.

[15] Bhatia, D., Datta, D., Joshi, A., Gupta, S., Gote, Y. 2018. Adsorption study for the separation of isonicotinic acid from aqueous solution using activated carbon/Fe304 composites. Journal of Chemical \& Engineering Data, Cilt 63(2), s. 436-445. 


\section{DEÜ FMD 23(68), 479-487, 2021}

[16] Datta, D., Sah, S., Rawat, N., Kumar, R. 2017. Application of magnetically activated carbon for the separation of nicotinic acid from aqueous solution Journal of Chemical \& Engineering Data, Cilt 62(2), s. 712-719.

[17] Dancu, A.C., Barabas, R., Bogya., E.S. 2011. Adsorption of nicotinic acid on the surface of nanosized hydroxyapatite and structurally modified hydroxyapatite. Central European Journal of Chemistry 9, Cilt 4, s. 660-669.

[18] Tian, H.W., Li, W.H., Wang, D.P., Hou, B.R. 2012. Adsorption mechanism of nicotinic acid onto a passive iron surface. Acta Physico-Chimica Sinica, Cilt 28(1), s. 137-145.

[19] Guo, Z., Zhu, G., Gao, B., Zhang, D., Tian, G., Chen, Y., Zhang, W., Qiu, S. 2005. Adsorption of vitamin B12 on ordered mesoporous carbons coated with PMMA. Carbon, Cilt 43 (11), s. 2344-2351.

[20] Kang, J., Zhan, W., Li, D., Wang, X., Song, J., Liu, D. 2011. Integrated catalytic wet air oxidation and biological treatment of wastewater from Vitamin B6 production. Physics and Chemistry of the Earth Parts A/B/C, Cilt 36(9-11), s. 455-458.

[21] Gadipelly, C., Pérez-González, A., Yadav, G.D., Ortiz, I. Ibáñez, R., Rathod, V.K., Marathe, K.V. 2014. Pharmaceutical industry wastewater: review of the technologies for water treatment and reuse. Industrial \& Engineering Chemistry Research, Cilt 53(29), s. 11571-11592.

[22] Mohammad, A., Inamuddin, Amin, A., Naushad, M., El-Desoky, G.E. 2013. Nicotinic Acid Adsorption Thermodynamics Study on Carboxymethyl Cellulose Ce(IV) Molybdophosphate Composite CationExchanger. J. Therm. Anal. Calorim., Cilt 111, s. 831-838.

[23] Cantarella, L., Gallifuoco, A., Malandra, A. Martínková, L., Spera, A. and Cantarella, M. 2011. High-yield continuous production of nicotinic acid via nitrile hydratase-amidase cascade reactions using cascade CSMRs. Enzyme and microbial technology, Cilt 48(4-5), s. 345-350.

[24] Anbia, M., Parvin, Z., Sepehrian, M. 2019. Application of modified nanoporous materials in ascorbic acid adsorption. Particulate Science and Technology, Cilt 37(6), s. 750-756.

[25] Terzi, S.M. 2018. Aktif Karbon Üzerinde Nikotinik Asit Adsorpsiyonunun İncelenmesi. Marmara Üniversitesi, Sağlık Bilimleri Enstitüsü, Yüksek Lisans Tezi, 75 s, İstanbul.

[26] Noh, J.S., Schwarz, J.A., 1989. Estimation of the point of zero charge of simple oxides by mass titration. J. Colloid Interface Sci., Cilt 130, s. 157-164.

[27] Gritti, F., Guiochon, G. 2009. Characteristics of the adsorption mechanism of acido-basic compounds with two $\mathrm{pKa}$ in reversed-phase liquid chromatography. Journal of Chromatography A., Cilt 1216 (41), s. 6917-6930.

[28] Giles, C.H., Macewan, T.H., Nakhwa, S.N., Smith, D.J, 1960. Studies in adsorption. Part XI. A system of classification of solution adsorption isotherms, and its use in diagnosis of adsorption mechanisms and in measurement of specific surface areas of solids. J. Chem. Soc., Cilt 786, s. 3973-3993.

[29] Salihi, E.C. and Mahramanlığlu, M., 2014. Equilibrium and kinetic adsorption of drugs on bentonite: Presence of surface active agents effect. Applied Clay Science, Cilt 101, s. 381-389.

[30] Gök, O., Çimen Mesutoğlu, Ö. 2018. Adsorpsiyon Kolon Sisteminde Pirina Kullanılarak Ağır Metal Giderimi. Dokuz Eylül Üniversitesi-Mühendislik Fakültesi Fen ve Mühendislik Dergisi, Cilt 20, Sayı 60, s. 1000-1009.

[31] Calıskan Salihi, E. and Aydın, E. 2017. Adsorptive characteristics of isoniazid on powdered activated carbon: $\pi-\pi$ Dispersion interactions at the solidsolution interface. Journal of Dispersion Science and Technology, Cilt 38(4), s. 457-462. 